\title{
MUSIC ELICITATION
}

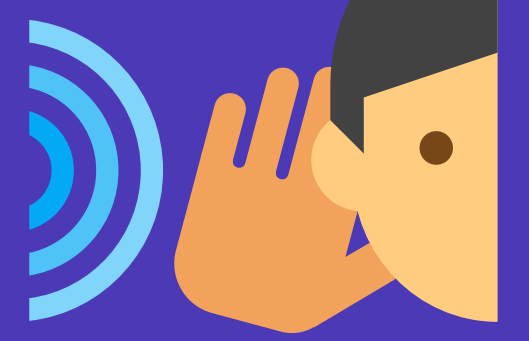

As a narrative research and listening tool

Findings from Levell (2019)

\section{RESEARCH WITH MARGINALISED GROUPS FOUND:}

\section{MUSIC CAN FUNCTION AS} AN ANCHOR TO MEMORIES

Participants described music as a tool they used in the past for coping, solace, and support. Co-listening to tracks can provide a visceral anchor to these memories.

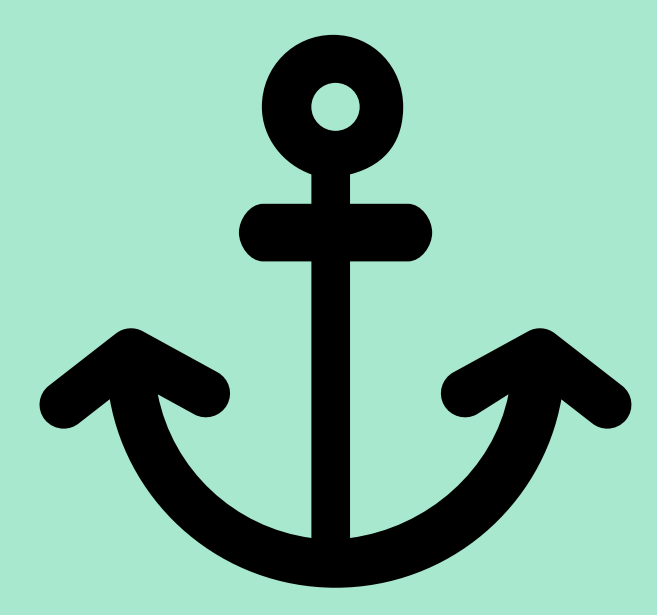

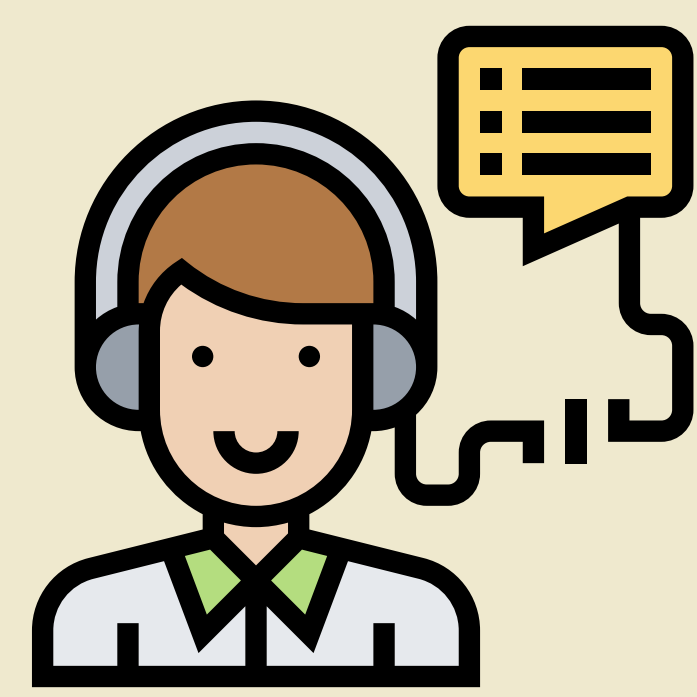

MUSIC ELICITATION AS A NARRATIVE TOOL

Music elicitation as an unstructured interview tool enables participants to curate the interview space and chapter their story using the tracks to separate their narratives.

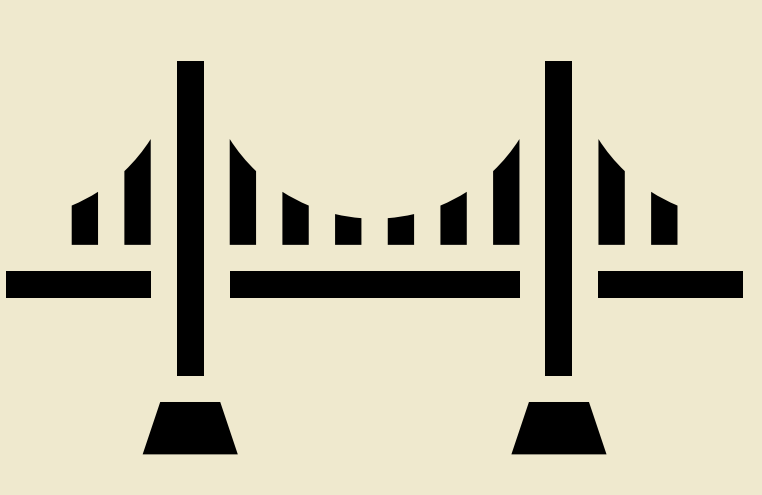

\section{MUSIC CAN FORM A BRIDGE} OF UNDERSTANDING

Co-listening can be a powerful shared experience. It creates a common ground and puts the participant in the position of curator, host, and expert in the room.

\section{LISTENING}

